\title{
CRIMINALIZACIÓN DE LA ECONOMÍA INFORMAL EN LAS FRONTERAS SUDAMERICANAS. \\ ESTUDIO DE CASO DE LA TRIPLE FRONTERA DEL PARANÁ Y LA TRIPLE FRONTERA CENTRAL SUR ANDINA
}

\author{
CRIMINALIZATION OF THE INFORMAL ECONOMY ON THE SOUTH AMERICAN \\ BORDERS. \\ CASE STUDY OF THE TRIPLE FRONTIER OF PARANÁ AND THE SOUTH ANDEAN \\ TRIPLE CENTRAL FRONTIER
}

\author{
Ricardo Jiménez Palacios* \\ Universidad Privada de Tacna, \\ Tacna - Perú. \\ Recibido septiembre de 2018/Received September, 2018 \\ Aceptado agosto de 2019/Accepted August, 2019
}

\begin{abstract}
RESUMEN
El artículo se propone explorar las dinámicas de criminalización de la economía informal en dos territorios fronterizos sudamericanos, dialogando con la producción académica sobre estos territorios durante la última década. Para ello hemos abordado dos circuitos informales de comercio fronterizo en el Mercado de Abastos del Barrio Obrero (Ciudad del Este, Paraguay en la Triple Frontera del Paraná) y la Feria de Ropa y Calzado de Segundo Uso (Tacna, Perú en la Triple Frontera Central Sur Andina). El diseño comparativo y cualitativo de la investigación nos permite evidenciar y profundizar sobre las percepciones de los actores fronterizos en torno a las dinámicas de exclusión laboral producto de la reestructuración económica en los territorios de frontera sudamericanos, permitiéndonos dialogar no solamente con la producción académica actual sino además con las políticas públicas comerciales y productivas instaladas en ambos territorios fronterizos.
\end{abstract}

Palabras Clave: Ciudad del Este, Tacna, Criminalización, Informalidad, Fronteras.

\begin{abstract}
The article aims to explore the dynamics of criminalization of the informal economy in two South American border territories, discussing with academic production about these territories during the last decade. For this we have addressed two informal circuits of border trade in the Market of Supplies of the Barrio Obrero (Ciudad del Este, Paraguay in the Triple Border of the Paraná) and the Fair of Clothing and Footwear of Second Use (Tacna, Peru in the Triple Central Border Andean South). The comparative and qualitative design of the research allows us to demonstrate and deepen the perceptions of the border actors around the dynamics of labor exclusion resulting from the economic restructuring in the South American border territories, allowing us to discuss not only with the current academic production but in addition to commercial and productive public policies in both border territories.
\end{abstract}

Key Words: Ciudad del Este, Tacna, Criminalization, Informality, Borders.

* Autor correspondiente / Corresponding author: jpricardojp@gmail.com / rjimenezp@upt.pe 


\section{INTRODUCCIÓN}

El presente texto forma parte de la investigación de la tesis "Criminalización de la Economía Informal en las Fronteras Sudamericanas: Estudio de caso de la Triple Frontera del Paraná y la Triple Frontera Central Sur Andina" presentada para obtener el grado de maestría en Integración Contemporánea de América Latina por la Universidade Federal da Integração Latino Americana (UNILA). La investigación se desarrolló por medio de una estrategia cualitativa en base a entrevistas, la observación participativa y la revisión documental, generándose una serie líneas de análisis críticos en relación a los estudios fronterizos.

Tanto la Triple Frontera del Paraná (Brasil, Paraguay y Argentina) como la Triple Frontera Central Sur Andina (Perú, Chile y Bolivia) han sido abordadas indistintamente por la academia de cada una de los países en mención, con especial énfasis de Brasil en el primer caso y de Chile en el segundo. Sin embargo, los lugares de enunciación de los abordajes investigativos conllevan a una mayor atención sobre sus ciudades nacionales, reconstruyendo circuitos y dinámicas fronterizas a partir de sus estudios de caso nacional por sobre otros corredores y dinámicas transfronterizas que permitirían evidenciar las nuevas desigualdades y complejidades territoriales en el marco de reestructuración económica del neoliberalismo.

Así, el enfoque comparativo de investigación resulta importante no solo porque discute con la producción académica de estudios fronterizos a nivel sudamericano, sino porque además permite evidenciar dinámicas de criminalización invisibilizadas en el contexto de transformación productiva y económica de los territorios fronterizos en el contexto de las políticas de ajuste estructural. Ello último debido a que la muestra de otros corredores fronterizos permite generar indicios sobre nuevas territorialidades y dinámicas fronterizas poco visibilizadas por discusión científica actual.

Asimismo, el diseño cualitativo de la investigación permite profundizar sobre estas dinámicas poniendo en debate las políticas públicas instaladas en los territorios de frontera estudiados, permitiendo un debate no solo de la teoría sino además de la agenda pública que viene asentándose en los territorios de frontera sudamericanos desde hace poco más de una década.
Finalmente, el presente texto se dividirá en tres pilares clave: discusión conceptual, aspectos metodológicos y resultados. La discusión conceptual explora teorías en torno a la criminalización, las sociedades de control, la informalidad y las exclusiones laborales en el contexto de fronteras. La parte metodológica se inicia con una revisión crítica de los antecedentes, así como la estrategia metodológica y el diseño de presentación de resultados. Por último, los resultados y conclusiones dan cuenta del trabajo de campo realizado por medio de entrevistas a dirigentes sociales y comerciantes.

\section{DISCUSIÓN CONCEPTUAL Dinámicas de criminalización en los territorios fronterizos}

Si bien el abordaje de la criminalización se ha desarrollado principalmente en torno a la relación entre extractivismo, neoliberalismo y protestas sociales (Betancur, 2006; Svampa \& Pandolfi, 2004), existe también producción académica en relación a la criminalización de pueblos indígenas (Radcliffe \& Webb, 2016; Aylwin, 2008), juventud y raza (Ríos, 2006), políticas de drogas (Epele, 2007; Duke, 2006; Osuna, 2013), práctica del aborto (Hein de Campos, 2011) y población LGBTI (Han \& O' Mahoney, 2014).

No obstante, más allá de ser un fenómeno exclusivo de nuestro sistema económico o época, podemos explorar este concepto a través del tránsito entre las sociedades disciplinarias (Foucault, 2012) y las sociedades de control (Deleuze, 1991). Pues, como apunta Gilles Deleuze (2014), aunque Foucault trató de manera magistral las sociedades disciplinarias por medio de las técnicas de encierro, debemos indicar que subyace una explicación medular en relación al resquebrajamiento de las sociedades disciplinarias y el afianzamiento de las sociedades de control.

A diferencia de la disciplina, caracterizada por el encierro, las sociedades de control suponen un espacio abierto donde grandes multiplicidades de población son administradas por medio de escalas probabilísticas (Deleuze, 2014). De manera que, a las luces de las sociedades de control de poblaciones, podemos considerar que las formas de criminalización no se reducen únicamente al encierro, las lesiones o la muerte, sino que suponen una serie de dispositivos gubernamentales que administran la vida por medio de las probabilidades poblacionales. 
Ello, en relación a la frontera, implica un territorio y una población administrada. Administración que ha transitado de una perspectiva en clave soberana nacional a una "concepción de fronteras como regiones de integración [suponiendo] un cambio en el enfoque de la gestión fronteriza, el cual ahora prioriza el desarrollo económico" (Dammert, Bensús, Sarmiento, \& Prieto, 2017, p.138).

De manera que, suponer las dinámicas de criminalización en las fronteras, implica la administración poblacional por medio de políticas gubernamentales instaladas en los territorios fronterizos. El control poblacional en las fronteras guarda una relación directa con la concepción que se tenga de estos territorios; así, si hoy por hoy la consideramos como una región de integración económica, la población a administrar estará constantemente controlada en el cumplimiento de estos fines.

De esta manera podemos distinguir la promoción de determinadas actividades económicas, comerciales y productivas ancladas territorialmente en las fronteras de estudio, como además actividades económicas, comerciales y productivas que han de ser prohibidas legal y socialmente. Por lo tanto, las dinámicas de la criminalización en los territorios fronterizos se manifestarán en dispositivos legales, decomisos, abusos o agresiones, así como declaraciones acusadoras e incriminadoras, muestra de los mecanismos de control formal e informal.

Comprender las dinámicas de criminalización de la informalidad en las fronteras, manifiestas en la transición hacia el control de las poblaciones en pro del desarrollo económico y la creación de valor, implicará además comprender el proceso de cambio de las economías informales hacia las dinámicas de exclusión laboral (Pérez y Mora, 2004).

\section{De la economía informal a la exclusión laboral}

Diversos autores (Mendoza, 2003; Portes \& Haller, 2004; Clot, 2013; Ireland, 2015) coinciden que la economía informal empieza a ser un problema de estudio desde el año 1972, cuando un reporte de la Organización Internacional del Trabajo (ILO, 1972) dio cuenta que las estadísticas laborales oficiales obviaban a una serie de trabajadores y asalariados por cuenta propia, a quienes se les empezó a denominar sector informal (ILO,
1972). Además, se consideraba que la informalidad estaba compuesta, por pequeños comerciantes, vendedores ambulantes, lustra botas, entre otros grupos dentro del subempleo; de forma paralela, el informe de la OIT refiere que el sector informal no está compuesto únicamente por la producción marginal, sino que resulta un fenómeno complejo económicamente eficiente en pequeña escala y con pequeños capitales, en relación al sector formal (ILO, 1972).

Hacia la década de 1990, se desarrollarán dos perspectivas contrastadas en torno a la economía informal (Cruise, 2009). Una trabajada por el sociólogo cubano Alejandro Portes donde la economía informal favorecerá a una pequeña élite que se beneficia de la acumulación de capital generada por la subcontratación en la producción y venta de insumos y bienes. Mientras que la otra perspectiva, desarrollada por el economista peruano Hernando de Soto, considera lo contrario; donde una pequeña élite, al no permitir la apertura del mercado, genera las dinámicas económicas informales.

No obstante, la dicotomía formalidad/informalidad meditada durante las décadas del setenta (Hart, 1990), ochenta y noventa (Rosenbluth, 1994; Mendoza, 2004) resulta heredera de una práctica y percepción de un mercado laboral consolidado bajo el modelo de industrialización por sustitución de importaciones, heredero de un marco político territorial en clave nacional (Pérez $\&$ Mora, 2004). Hoy por hoy, bajo un contexto de declive de la escala nacional (Jessop, 2004) y tras los procesos de ajuste estructural, el análisis de las desigualdades en el mercado laboral debe ser replanteado.

El abordaje dicotómico de las desigualdades manifiestas en el mercado laboral implicaba la posibilidad que el trabajador informal en algún momento se inserte en el mercado formal. Sin embargo, los procesos de ajuste estructural han conllevado a la pérdida del eje del mercado laboral formal hacia una situación marcada por la exclusión laboral, la reestructuración productiva y las economías de supervivencia.

Es así como la criminalización de la economía informal en las fronteras implicará la lectura de dos importantes procesos de transformación. El primero de ellos en referencia al tránsito de las sociedades disciplinarias a las sociedades de control, esto reúne a formas de criminalización 
propiamente disciplinarias como el encierro, las lesiones o la muerte, así como a formas de criminalización de control poblacional, manifiestos en las políticas fronterizas y las políticas de restricción comercial reflejadas en los controles aduaneros y migratorios.

Por otro lado, el segundo proceso de transformación guarda íntima relación entre las políticas de desarrollo e integración económica fronteriza con la reestructuración productiva manifiesta en las políticas de restricción comercial y productiva. El papel que cumplen los territorios fronterizos en medio de la reestructuración económica y productiva genera una situación que va más allá de la dicotomía formalidad/informalidad, generando economías de supervivencia de fronteras a partir de las exclusiones laborales que generan las políticas de desarrollo e integración económica de fronteras. Para visibilizar este proceso de criminalización de la economía informal en fronteras, hemos tomado los estudios de caso en la Triple Frontera del Paraná (Brasil, Argentina y Paraguay) y la Triple Frontera Andina (Perú, Chile y Bolivia), concentrándonos en dos circuitos comerciales informales que construyen su eje de acción en torno al Mercado de Abastos del Barrio Obrero (Ciudad del Este, Paraguay), en la frontera paranaense, y la Feria de Ropa y Calzado de Segundo Uso (Tacna, Perú), en la frontera andina.

\section{Aspectos Metodológicos}

La revisión de la producción teórica y científica nos lleva a identificar que parte de ésta se concentra en determinados países de las triples fronteras en estudio. Así, la Triple Frontera del Paraná concentra su producción en la academia brasileña (Cardin, 2006; Rabossi, 2004; Albuquerque, 2008; Cardin, 2013; Fiorotti, 2013; Núñez et al., 2017; Cardin \& Fiorotti, 2018), mientras que la Triple Frontera Central Sur Andina concentra su producción en la academia chilena (Valdebenito \& Guizardi, 2014; Guizardi, Heredia, Muñoz, Riquelme \& Valdebenito, 2014; Guizardi, Valdebenito, López, \& Nazal, 2017; Tapia, Liberona, \& Contreras, 2017; Liberona, Tapia, \& Contreras, 2017; Valdebenito, 2018; Dilla \& Álvarez, 2018; Garcés et al., 2018), suponemos que esto implica el análisis de determinados corredores fronterizos que tienen sus ejes principales tanto en Brasil como en Chile, siendo un escenario constante el análisis de los sacoleiros (Cardin, 2006), así como los brasiguaios (Albuquerque, 2008), mientras que en el caso andino el protagonismo se concentra en determinados puntos de la ciudad de Arica (Guizardi et al., 2014) o las experiencias de la movilidad de chilenos por motivos de salud (Liberona et al., 2017).

Si bien se hacen esfuerzos por desarrollar análisis transfronterizos, el núcleo académico en Brasil y Chile determina los corredores analizados, desatendiéndose otros corredores y dinámicas fronterizas concentradas en otros contextos como el tacneño o esteño ${ }^{1}$. Es por ello que decidimos concentrar el estudio de las dinámicas de criminalización de la economía informal en los contextos invisibilizados por la academia, los distritos periféricos de la ciudad de Tacna ${ }^{2}$ y los barrios aledaños a Ciudad del Este, donde también existen importantísimas dinámicas fronterizas. De ahí que nuestros objetos de estudio sean dinámicas fronterizas ancladas en estas dos ciudades, particularmente la Feria de Ropa y Calzado de Segundo Uso en la ciudad de Tacna (Perú) y el Mercado de Abastos de Ciudad del Este (Paraguay).

La estrategia metodológica fue cualitativa, a través de la revisión documental de leyes, decretos y resoluciones en relación a las actividades económicas informales estudiadas, entrevistas semiestructuradas a dirigentes gremiales y comerciantes, además de la observación participante, en tanto construcción participativa y continua de sentido $^{3}$ (Brockmann, 2011).

En la siguiente sección expondremos los resultados tomando en cuenta las dinámicas de criminalización o control social (García-Pablos de Molina, 2003), iniciando con la exposición de leyes, decretos y resoluciones en mención, seguido de los relatos de abuso de autoridad y noticias que den cuenta de las mismas. Asimismo, la exposición de las dinámicas de informalidad nos permitirá acercarnos a las situaciones de exclusión laboral (Pérez \& Mora, 2004) en el marco de la reestructuración productiva y económica de los territorios fronterizos. Finalmente, es importante referir que la investigación base (Jiménez, 2018) resulta más amplia centrándonos, en esta ocasión, únicamente en las dinámicas de criminalización de las economías informales.

\section{RESULTADOS}

Si bien las dinámicas de criminalización de la economía informal pueden desenvolverse por medio de diversos mecanismos de control; la 
muerte, producto del abandono y la invisibilización de corredores fronterizos y sus actores, es una de las muestras más descarnadas de los límites territoriales.

Según las investigaciones, Víctor Perlacios conducía el vehículo Toyota blanco de placa TK-2679, perteneciente a la empresa de radiotaxi El Galeón, que presionó una mina antitanque en suelo chileno, a unos $600 \mathrm{~m}$ de los hitos 13 y 14 en la línea fronteriza, en la quebrada de un río seco.

El año 2012 la Policía chilena indicó que el vehículo al parecer retornaba al Perú por un paso no habilitado en el desierto, como una forma de evadir un control aduanero. (Chatta, 2016, párr. 3).

Las historias de muerte y accidentes fata$\mathrm{les}^{4}$ en torno a la informalidad fronteriza se ven acompañadas por otros sucesos que van desde la prisión $^{5}$, los decomisos ${ }^{6}$ y el acoso institucional ${ }^{7}$. Así, por ejemplo, el miedo permanente que los sacoleiros $^{8}$ sienten ante la posibilidad de ser asaltados, de sufrir un accidente o de morir (Rabossi, 2004) hasta el acoso registrado en operativos de las Aduanas peruanas hacia los comerciantes en horas de madrugada (Vega, 2012) se erigen como posibles medidas ante el precio de su actividad.

La nota periodística citada nos muestra una serie de fragmentos de interpretación, más allá de la gama de formas de criminalización mencionadas, la nota da cuenta de minas antitanques, líneas fronterizas y pasos no habilitados. Consideramos que dichos elementos nos muestran una fotografía del momento, como una pieza interesante a partir de la cual podemos referir una breve explicación genealógica.

La línea fronteriza y las minas antitanques, propias del posible escenario bélico entre Perú y Chile durante las décadas de 1970, dan cuenta de una visión de la frontera en tanto dispositivo de defensa y soberanía, el cual es adoptado durante gran parte de la historia republicana. Por otro lado, los pasos habilitados, en el escenario actual, dan cuenta de un escenario de integración o apertura que sin embargo no deja de ser controlada, produciendo porosidad en los territorios fronterizos a través de los flujos y economías locales (Garcés, González, Richard \& Soto, 2018).

Ahora bien, aunque las prácticas económicas informales y las restricciones legales en torno a ellas se han dado en diversos momentos de nuestra historia (Jiménez, 2018), pretendemos enfocar las dinámicas de criminalización de la economía informal desde las reformas de ajuste neoliberal durante las últimas décadas del siglo veinte.

Así tendrían que existir ciertos instrumentos normativos que excluyan a las actividades no funcionales en las zonas de frontera estudiadas (Ferias de Ropa Usada / Mercado de Abastos). Finalmente, las leyes que excluyan estas actividades, vendrían a formalizar una realidad anhelada a partir de las políticas económicas y comerciales neoliberales.

Las Ferias de Ropa y Calzado de Segundo Uso tienen su origen en la actividad de los ropavejeros ${ }^{9}$ que, aunque cotidiana y local, adquirirá matices transfronterizos gracias al intercambio de enseres de plástico provenientes de Tacna, a cambio de ropa, zapatos y herramientas usadas, provenientes de Arica; todo ello en el marco del Régimen Especial de Frontera vigente desde el Tratado de Lima de $1929^{10}$. La apertura de la Zona Franca de Iquique tornará novedosa la actividad de los ropavejeros tacneños en tanto que podían solicitar a sus caseros ariqueños ropa americana que llegaba al puerto de Iquique.

Sin embargo, durante la década de 1990, un conjunto de dispositivos jurídicos restringirá una serie de actividades fronterizas, mientras que priorizará otras. Así, en el año 1992 el Decreto Ley No 25789 (1992) que "Deroga todas las disposiciones que prohíban o restrinjan la importación de bienes usados" suspendía la importación de ropa y calzado de segundo uso de manera indeterminada, siendo hasta el año 1998 que la Ley N 26975 precisará el plazo de suspensión para el año 2005. Asimismo, es importante detallar que la década del noventa significará, para las fronteras peruanas, el período de modificación de sentido de una frontera de soberanía a una frontera neoliberal o frontera del container ${ }^{11}$ (Jiménez, 2018; Jaquet, 2008), situación que quedará cristalizada con el Decreto Legislativo $\mathrm{N}^{\circ} 842$ del 30 de agosto de 1996, el cual declara de interés prioritario el desarrollo de la zona sur del país y crea los $\operatorname{CETICOS}^{12}$ y la Zona Franca de Tacna.

De esta manera se construirá un Régimen General de exportación en la frontera sur, frente al Régimen Especial de Frontera vigente desde 1929, siendo afectadas las diversas actividades económicas locales de frontera. Un antiguo dirigente comerciante nos relata esa experiencia. 
[Antiguo Dirigente Comerciante]: Todo venía, en conteiner venía todo pues, en un conteiner eran puros alimentos, fruta y atrás 3 vagones venían. Poco a poco nos han venido eliminando, y yo pensaba mira, ¿qué pasa ahora? El gobierno nos elimina a los chicos, pero a los grandes después los veíamos entrando por tráiler. Yo decía, ¿Cómo está entrando acá? ¿Y a nosotros cómo nos corta? Ellos como, que, ¡serán capitalistas! (risas) por eso será pues. Porque yo miraba no más... Después cortaron creo artefactos, unas 100 personas también eran, decían: "No puede entrar eso" y ahí quedó. [Entrevistador]: ¿Y ahí se formaron los mercadillos? [Antiguo Dirigente Comerciante]: Ajá, a los mercadillos, sí. Algunos se han quitado, la mayoría se quitó, porque ya no tenías plata. Ya después vino la fruta, igual, cortaron, " $; Y a$ !, ipor régimen!", por régimen. Después vino, a las bicicletas, mallas, los cilindros grandes, eso también entraba y nos cortó. Igualito veo que en Santa Rosa (Paso fronterizo) entraban los tráilers haciendo cola de todo, de malla, etc. Por ejemplo, malla, decían "No puede entrar", pero después importaron los grandes diciendo que hicieron un convenio... Pero yo no sé, yo no entiendo. Así nos han eliminado todo, de todo nos han eliminado. [Entrevistador]: ¿Y la última cual fue? [Antiguo Dirigente Comerciante]: La ropa, hasta el último nosotros nos quedamos en la ropa, pero ya con la sentencia, ya no se ya, se nos eliminó pues.

La denominada sentencia hace referencia al Expediente $\mathrm{N}^{\circ}$ 0031-2005-PI/TC por medio del cual el Tribunal Constitucional reafirmaba la prohibición de la ropa y calzado de segundo uso. El año 2005, tal como lo determinaba la Ley №26975, se promulgó la Ley 28514 Ley que Prohíbe la Importación de Ropa y Calzado de Segundo Uso.

La promulgación de la Ley № 28514 desencadenó movilizaciones de las diversas asociaciones de comerciantes de ropa y calzado de segundo uso en la ciudad de Tacna. Si bien no se pudo derogar la ley sí se presionó al Gobierno Regional para que emita una norma local que permitiera el comercio de ropa y calzado de segundo uso (Ordenanza Regional No 009-2005-CR/GOB.REG.TACNA, publicada en julio del 2005).

Debe tomarse en cuenta que esta Ordenanza Regional será denunciada por la Presidencia de la
República ante el Tribunal Constitucional el mes de setiembre del mismo año, argumentándose en torno a la promoción de la libre competencia frente a la competencia prohibida, así como a la protección de la salud pública ${ }^{13}$ (Presidente de la República vs Gobierno Regional de Tacna, Exp. $\mathrm{N}^{\mathrm{o}}$ 0031-2005-PI/TC, 20 de marzo de 2007) .

Finalmente, el 20 de marzo del 2007, el Tribunal Constitucional falla a favor de la Presidencia de la República. Durante los últimos doce años la situación jurídica de los feriantes es criminalizada institucionalmente, desencadenándose a partir de ellas otros mecanismos de criminalización y control informal desde los medios de comunicación, grupos de poder económico, además de hechos de violencia física, verbal o abuso de autoridad.

En el caso paranaense existe una figura similar a la apertura de la frontera, a partir de la cual se irán generando prohibiciones y restricciones en torno a intereses económicos y comerciales ajenos a una dinámica local. A diferencia de la ciudad de Tacna, Ciudad del Este se originó geopolíticamente en la década de 1970, con los megaproyectos de infraestructura binacional. Así, el Mercado de Abastos de esta ciudad se encuentra en el núcleo inicial de la misma, en el llamado Barrio San José Obrero, donde se albergaban los trabajadores de la Represa Binacional de Itaipú.

El Mercado de Abastos del Barrio Obrero se constituyó en la fuente de suministro de la joven ciudad la cual se proveía de las ciudades vecinas de Foz de Iguaçu (Brasil) y Puerto Iguazú (Argentina). Uno de los primeros inmigrantes esteños refiere.

[Investigador] Y cuando usted vino para
acá, me dice que eran pocos todavía, en el 75
más o menos ¿Qué tal era el tema de abaste-
cimientos de alimentos, abastecimiento de
productos? ¿Cómo hacían para conseguirlo
en una ciudad que recién se iba haciendo, no?
[Vecino del Barrio Obrero] Sí, y realmente
en los primeros tiempos, más en parte para
el sustento familiar, alimento y todo se traía
de Brasil, toda la compra se hacía en Brasil.

Así, el abastecimiento de Ciudad del Este se originará en el contrabando fronterizo de alimentos, el cual será regulado posteriormente por el Régimen de Tráfico Vecinal Fronterizo desde el año $2014^{14}$ (Decreto $N^{\circ} 2431$ del Ministerio de Hacienda de Paraguay). Al igual que el Régimen 
General y la Zona Franca de Tacna, el Régimen de Tráfico Vecinal Fronterizo se constituirá en un supuesto dispositivo de apertura comercial que flexibilizará las prohibiciones locales de comercio fronterizo.

Así, la Resolución Nº444-16 de la Dirección Nacional de Aduanas de Paraguay formaliza una situación determinada a escala nacional, en tanto protección de los productos originarios, así como de aquellos importados. La Resolución $\mathrm{N}^{\circ} 444$ del 13 de setiembre del 2016 refiere sobre la Exclusión de los Productos de Origen Vegetal en Estado Natural del Tratamiento Aduanero bajo el Régimen de Tráfico Vecinal Fronterizo.

El Régimen de Tráfico Vecinal Fronterizo, ideado para facilitar el suministro de la población de frontera para el uso personal o familiar ${ }^{15}$ se ve modificado por políticas comerciales inspiradas en una concepción territorial a nivel global (Jiménez, 2018). De la misma forma que en el caso peruano, las prohibiciones paraguayas generarán un halo de impunidad entre abusos de autoridad, segregaciones espaciales, acoso y hechos de violencia que hemos venido a agrupar en la criminalización o control social informal.

$\mathrm{Si}$ bien en otras ocasiones se hace referencia a los decomisos de mercancías (Cfr. "Hallan carro con ropa", 2017; Cardin, 2006) debemos considerar que este fenómeno no se limita a la línea fronteriza, sino que implica al territorio fronterizo en su totalidad. Así en el caso de Tacna, si bien el decomiso en el Paso Fronterizo de Santa Rosa es una constante, ésta no se da únicamente por los agentes de aduana, sino que se extiende a otros actores como la policía y los agentes municipales, quienes además incautan las mercaderías al interior de la ciudad. Al consultarle a un dirigente comerciante sobre los decomisos y otras dificultades dificultades, este refirió.

[Dirigente Comerciante] En la feria no, pero cuando trasladan de acá a su casa o en la tarde suben de Cenepa o bajan de acá, sí, siempre molestan, la gente está pensando que siempre pueden venir, que no está permitido, siempre nos dicen, pero nunca viajamos tranquilamente nosotros, sino que siempre viajamos con ese temor.
Asimismo, en algunas ocasiones las historias de decomiso ya en la línea fronteriza ya en la ciudad vienen acompañadas de relatos de agresión.

[Antiguo Dirigente Comerciante]: No, Aduanas, siempre aduanas, pero antes eran bien malos, ahora ya siquiera un poquito se han civilizado. [Entrevistador]: ¿Qué hacían? [Antiguo Dirigente Comerciante]: Pucha, antes nos quitaban todo, todo, todo nos quitaba, no pasaba nada que no fuera autorizado. [Entrevistador]: ¿Llegó a haber agresión? [Antiguo Dirigente Comerciante]: $\mathrm{Si}$, bastante, eran bien malos, bien malos. [Entrevistador]: ¿Se quedaban con las cosas? [Antiguo Dirigente Comerciante]: Sí, se quedaban... Los que pagaban al aduanero, pasaban, los que no pagaban, no pasaban.

A diferencia de ello, en el caso del Mercado de Abastos de Ciudad del Este, no se da cuenta de experiencias de decomiso al interior de la ciudad, más sí en la línea de frontera. Una comerciante de ropa del Mercado de Abastos, nos refiere lo siguiente.

[Comerciante mujer]: Además que también son productos nacionales y también son productos brasileros, también. Ahora hay mucho control en la aduana y no te puedes arriesgar así no más, hay mucha gente que se arriesga a traer y pierde.

Si bien pareciera que el decomiso únicamente sucede en la línea fronteriza, para el caso paranaense, debemos clarificar algunos asuntos. En primer lugar, la diferencia entre el Mercado de Abastos y las Ferias de Ropa y Calzado, mientras que la segunda es itinerante, la primera se da en puestos de venta fijos; ello puede resultar un elemento clave al momento de las incautaciones por otros agentes municipales o de gobierno. Asimismo, el mayor acercamiento al fenómeno andino permitió estrategias metodológicas más sólidas que permitan visibilizar de manera más profunda este escenario que el paranaense; así, el débil acercamiento a otros actores esteños como los mesiteros o vendedores de fruta no nos permiten una comparación más consistente en cuanto a los decomisos dentro de la ciudad.

Sin embargo, las historias de decomisos y violencia van de la mano con otras manifestaciones informales de control social, como pueden ser las 
opiniones de grupos de poder y la segregación urbana. La red de Mujeres en Empleo Informal: Globalizando y Organizando (WIEGO, 2015) afirma que existen una serie de mitos en torno a los comerciantes ambulantes tales como lo caótico de la venta ambulante, la ocupación del espacio público como estrategia de evasión de impuestos, la contribución a la criminalidad y la suciedad, entre otros.

Esta serie de mitos encuentran un correlato significativo en discursos de grupos de poder, políticas de segregación urbana y respuesta movilizada de los sectores afectados ("Mesiteros" anuncian, 2013; Decreto ignora, 2012; "Cachineros" deberán pagar, 2018; "Cachineros" y ambulantes marchan, 2017). Sin embargo, la dinámica de la criminalización informal, y de forma particular en referencia a los discursos y prácticas segregadoras del espacio, varían respecto a cada ciudad (Jiménez, 2018).

Nuevamente, en el caso tacneño, al ser un comercio itinerante, las dinámicas de segregación urbana y discursos excluyentes, conllevarán al constante desplazamiento del comercio hacia las periferias de la ciudad.

[Antiguo Dirigente Comerciante]: Estadio, estadio Tacna pues, en Arias Aragüez, esa con el estadio, y más antes vendíamos en el Rospigliosi, en un mercadito, que ahora es galería, quedaba a espaldar del Colegio San Francisco de Asís, ahí adentro vendíamos, antes no era galería, era un canchón, ahí vendíamos a partir de las 5 hasta las 9 de la noche. [Entrevistador]: ¿Y cuándo se pasan para Polvos Rosados? [Antiguo Dirigente Comerciante]: De ahí nos vinimos porque nos botan, "Sabes qué, ustedes váyanse porque acá es centro y están dando una mala imagen", y nos vinimos a salida a Tarata y de ahí también nos botaron: "Acá es avenida..." dijeron y nos vinimos a Polvos, y de Polvos también nos botaron 4 cuadras más arriba, y ya de ahí, la gente se arrancó por su lado (risas).

El caso esteño no solamente refiere a un comercio asentado en el Mercado de Abastos, sino que además refiere a una conurbación más sólida de Ciudad del Este - Foz de Iguaçu, separados por un puente de setenta metros, a diferencia de Tacna - Arica, separados por cincuenta kilómetros de distancia. Esta situación implica que las acciones gubernamentales en Brasil tengan una incidencia directa en Ciudad del Este, desencadenando dinámicas de exclusión y resistencia ciudadana.

[Dirigente del FETACE ${ }^{16}$ ]: Nosotros dependemos netamente del turismo, más son brasileros, argentinos, pasan pero muy poco, entonces cuando hay algunas, como le dije, represiones de la aduana, ahí comienza a mermar un poco las ventas ya que las fiscalizaciones cuando ellos hacen son muy rigurosos. No respetan la cota oficial de 300 dólares, el comercio es casi nulo, esos son los momentos difíciles, cuándo comienza, o el real baja bastante, hasta que se vayan acostumbrando a la situación de acá. [Entrevistador]: Tengo entendido que por allá en el 2007, 2005 hubo una toma de puente incluso... [Dirigente del FETACE]: Sí, la toma del puente ha comenzado en el 95, en una oportunidad cuando comenzó las represiones, se bajaba la cota a 150 dólares, ahí comenzamos el primer cierre del puente, creo se cerró por 30 días el Puente de la Amistad, después también en el 2001, también la misma cosa, se cerró aproximadamente 15 días, en el 2006 también, es la última vez que se cerró, fue por 4 días el cierre de puente.

Así, si bien se tienen en común la existencia de prácticas criminalizadoras informales o de control social informal (García-Pablos de Molina, 2003), estas variarán en su comportamiento dependiendo de los sectores comerciales, su nivel de organización y respuestas, así como las implicancias de las políticas de una ciudad respecto a otra.

Por otro lado, el control social formal de las fronteras, permanece como una práctica ya sea en clave soberana o en clave integradora, renovando sus mecanismos respecto a los planteamientos de los centros económicos. Los relatos de criminalización evidencian una transición de formas propias de una sociedad disciplinaria a una sociedad de control; si bien siempre han existido dinámicas informales en ambas fronteras de estudio, es importante resaltar que los mecanismos de control manifiestos en las aduanas y políticas locales se tornan más estrictas ante la concepción de un territorio fronterizo creador de valor y desarrollo económico en el marco de las políticas de ajuste estructural. 


\section{CONCLUSIONES}

En conclusión, la economía informal presente en los territorios fronterizos atraviesa nuevas dinámicas de criminalización ante la transformación de los mecanismos de control poblacional que colocan a las fronteras como elementos clave del desarrollo económico en el marco de una restructuración productiva que promueve determinadas actividades económicas y comerciales, relegando hacia la ilegalidad otro tipo de economías de supervivencia propias de las dinámicas de exclusión laboral.

Como escenario propio de las sociedades de control, los dispositivos jurídicos irán modificando sus formas, permisiones y prohibiciones dependiendo del marco de reestructuración productiva.
Estos ámbitos formales de la criminalización generan un halo de impunidad, así como mecanismos informales de criminalización que son activados por grupos de poder, agentes de gobierno y otros actores sociales.

No obstante, resulta interesante observar que ante nuevas formas de criminalización y control de las poblaciones se reinventarán mecanismos de organización, resistencia y empoderamiento local. Por otro lado, estas evidencias no serían posibles sin el análisis comparado de corredores fronterizos alternos que permiten entender nuevas complejidades en el marco de las políticas de ajuste estructural y las desigualdades territoriales que producen. 


\section{Referencias}

"Cachineros" deberán pagar tasas y multas por ocupar calles. (14 de mayo de 2018). Diario Correo. Recuperado de https:// diariocorreo.pe/edicion/tacna/cachineros-deberan-pagar-tasas-y-multas-por-ocupar-las-calles-818838/

"Cachineros" y ambulantes marcha hoy en cono sur. (14 de marzo de 2017). Sin Fronteras. Recuperado de http://www.diariosinfronteras. pe/2017/03/14/cachineros-y-ambulantes-marcha-hoy-en-cono-sur/

"Mesiteros" anuncian movilizaciones en el Este. (16 de febrero de 2013). Abc color. Recuperado de http://www.abc.com.py/ nacionales/mesiteros-anuncian-movilizacion-en-ciudad-del-este-539748.html

Albuquerque, L. (2008). Fronteiras e identidades em movimento: fluxos migratórios e disputa de poder na fronteira Paraguai-Brasil. Cadernos CERU, 2(19), 49-63.

Aylwin, J. (2008). La violencia y los derechos humanos de los pueblos indígenas. Revista d'estudis de la violencia, (4). Recuperado de www.cebem.org

Berganza, I. \& Cerna, M. (2011). Dinámicas migratorias en la frontera Perú - Chile. Arica, Tacna e Iquique. Lima, Perú: Universidad Antonio Ruiz de Montoya.

Betancur, M. (2006). Del estatuto de seguridad al estado comunitario: veinticinco años de criminalización de la protesta social en Colombia. Observatorio Social de América Latina, (19), 179-185.

Blanes, J. (2016). El subsistema fronterizo boliviano en la globalización de los mercados ilegales. La Paz, Bolivia: Centro de Estudios Disciplinarios, CEBEM.

Brites, W. (2018). ¿Ciudades gemelas? Posadas, Argentina y Encarnación, Paraguay en perspectiva sociourbana. Revista de Estudios Fronterizos, 19. doi: https://doi.org/10.21670/ref.1820020

Brockmann, M. (2011). Problematising short-term participant observation and multi-method ethnographic studies. Etnography and Education, 6(2), 229-243. doi: 10.1080/17457823.2011.587361

Cardin, E. (2006). Sacoleiros e 'laranjas' na tríplice fronterira: uma análise da precarização trabalho no capitalismo contemporáneo. Dissertação (Mestrado). Universidades Estadual Paulista, Araraquara/São Paulo.

Cardin, E. (2013). Mecanismos de contrabando y tráfico en la Triple Frontera. En F. Carrión \& V. Llugsha (comp.), Fronteras: rupturas y convergencias (pp. 255-266). Quito, Ecuador: Facultad Latinoamericana de Ciencias Sociales.

Cardin, E. \& Fiorotti, C. (2018). Dispositivos estatales, ilegalismos y prácticas sociales en la frontera Brasil-Paraguay (1890-2015). Revista de Estudios Fronterizos, 19. doi: https:// doi.org/10.21670/ref.1812012

Chatta, J. (14 de febrero de 2016). Tacna: la historia de los que salieron con la intención de trabajar y murieron en la frontera. Diario Correo Tacna. Recuperado de www.diariocorreo.pe

Clot, J. (2013). Acercamiento conceptual a las prácticas económicas informales en los pasos fronterizos entre México y Guatemala. Diacromie. Studi di Storia Contemporanea: Contrabbandieri, pirati e frontiere: per una storia delle pratiche informalli nell'America Centrale, (13). Recuperado de www.studistorici.com

Codoceo, F., Ampuero, F., \& Pérez, C. (2016). Criminalización de la Pobreza. La construcción política del sujeto peligroso. Osorno, Chile: Editorial Universidad de Los Lagos.
Comisión Interamericana de Derechos Humanos. (2015) Criminalización de la labor de las defensoras y los defensores de derechos humanos. Recuperado de www.derechos.org.ve

Cruse, R. (2009). L'Antimonde Caribeen, entre les ameriques et le monde. (Tesis de doctorado). Université de la Réunion, La Réunion/Francia.

Dammert, M., Bensús, V., Sarmiento, K., \& Prieto, G. (2017). Una aproximación a las fronteras desde los mercados ilegales en el Perú. Quito, Ecuador: Facultad Latinoamericana de Ciencias Sociales, Sede Ecuador.

Decreto ignora a "mesiteros" y solo favorece a los grandes empresarios. (06 de noviembre de 2012). Abc color. Recuperado de http:// www.abc.com.py/edicion-impresa/interior/decreto-ignora-a-mesiteros-y-solo-favorece-a-los-grandes-empresarios-474253.html

Deleuze, G. (1991) Posdata sobre las sociedades de control. En C. Ferrer (Comp.), El lenguaje literario. Montevideo, Uruguay: Ed. Nordan.

Dilla, H. \& Álvarez, C. (2018). Economía e intercambio desigual en una región transfronteriza: Arica-Chile - Tacna, Perú. Estudios Fronterizos, (19). doi: http://doi.org/10.21670/ref.1809009

Duke, K. (2006). Out of crime and into treatment? : The criminalization of contemporary drug policy since Tackling Drugs Together. Drugs: Education, Prevention and Policy, 13(5), 409-415. doi: 10.1080/09687630600613520

Epele, M. (2007). La lógica de la sospecha: sobre la criminalización del uso de drogas, complots y barreras de acceso al sistema de salud. Cuadernos de Antropología Social, (25), 151-168.

Fiorotti, C. (2015). Os descaminhos na fronteira: fiscais do Estado e trabalhadores nos procesos de apreensão de mercadorias na fronteira Brasil-Paraguai (1980-2015). Amivalências. Revista do Grupo de Pesquisa "Processos Indetitários e Poder", 3(5), 85-114.

Foucault, M. (2012). El poder, una bestia magnífica: sobre el poder, la prisión y la vida. Buenos Aires, Argentina: Siglo XXI.

Garcés, A., González, I., Richard, N., \& Soto, L. (2018). Formas porosas. Tiempos, movilidad y economías de frontera entre San Pedro de Atacama y Lípez. Revista de Dialectología y Tradiciones Populares, 63(2), 547-568. doi: https://doi. org/10.3989/rdtp.2018.02.013

García-Pablos de Molina, A. (2003). Tratado de Criminología. Valencia, España: Tirant Lo Blanch.

Graña, F. (2001). Cambio casera: comercio y relaciones fronterizas en el extremo norte de Chile. En Actas del $4^{\circ}$ Congreso Chileno de Antropología, Simposio Fronteras y Corredores. Recuperado de http://www.slideshare.net Acceso 18/02/2018

Guizardi, M., Heredia, O., Muñoz, A., Riquelme, G., \& Valdebenito, F. (2014). Experiencia migrante y apropiaciones espaciales: una etnografía visual de las inmediaciones del Terminal Internacional de Arica (Chile). Revista de Estudios Sociales, (48), 166-175. Recuperado de http://www.redalyc.org

Guizardi, M., Valdebenito, F., Nazal, E., \& López, E. (2017). Hyper-border spaces: peruvian migrants in the Arica Bus Terminal (Chile). Migraciones Internacionales, 9(1), 151-178. Recuperado de http://www.scielo.org.mx/pdf/migra/v9n1/16658906-migra-9-01-00151.pdf

Hallan carro con ropa de contrabando en la frontera con Chile. (11 de marzo de 2017). Diario Correo Tacna. Recuperado de www.diariocorreo.pe 
Han, E. \& O'Mahoney, J. (2014). British colonialism and the criminalization of homosexuality. Cambridge Review of Interntional Affairs, 27(2), 268-288. doi: http://doi.org/10.108 0/09557571.2013.867298

Hart, K. (1990). The Idea of Economy: Six Modern Dissenters. En R. Friedland \& A. Robeston (Eds.), Beyond the Marketplace: rethinking economy and society (pp. 137-164). New York, EUA: Walter de Gruyter.

Hein de Campos, C. (2011). Criminalización en masa por aborto: violación de los derechos reproductivos de las mujeres en Mato Grosso do Sul, Brasil. Recuperado de www.awid.org

International Labour Office. (1972). Employment, incomes and equality, a strategy for increasing productive employment in Kenya. Ginebra, Suiza: ILO.

Ireland, R. (2015). Introduction: borders, informality, international trade ands customs. Journal of Borderlands Studies, (30), 365-380.

Jaquet, H. (2008). Más allá de la frontera, las fronteras: Una aproximación socioespacial a las situaciones fronterizas de Misiones, Argentina. En H. Dilla (ed.), Ciudades de Frontera: Aproximaciones Críticas a los Complejos Urbanos Transfronterizos (pp. 31-66). Santo Domingo: Grupo de Estudios Multidisciplinarios Ciudades y Fronteras.

Jessop, B. (2004). La economía política de la escala y la construcción de las regiones transfronterizas. Revista Eure. Revista Latinoamericana de Estudios Urbano Regionales, 29(89), 25-41. Recuperado de http://www.eure.cl/index.php/ eure/article/view/1254

Jiménez, R. (2018). Criminalización de la economía informal en las fronteras sudamericanas. Estudio de caso de la Triple Frontera del Paraná y la Triple Frontera Central Sur Andina. (Tesis para optar el grado de maestro en Integración Contemporánea de América Latina). Recuperado de https://dspace.unila.edu.br

Liberona, N., Tapia, M., \& Contreras, Y. (2017). Modalidad por salud entre Tacna y Arica: análisis de una demanda no satisfecha y de una oferta atractiva del otro lado de la frontera. Geopolítica(s). Revista de estudios sobre espacio y poder, 8(2). Recuperado de http://revistas.ucm.es

Masi, S. (2017). Asimetrías y contradicciones en el uso del territorio en la frontera Praguay-Brasil. (Tesis de maestría). Recuperado de http://dspace.unila.edu.br

Mendoza, J. (2003). El TLCAN, el sector informal y los mercados de trabajo en la frontera norte de México. Comercio Exterior, (53), 1132-1139.

Montenegro, S. (2013). La Triple Frontera entre Argentina, Brasil y Paraguay. En F. Carrión \& V. Llugsha (comp.), Fronteras: rupturas y convergencias (pp. 241-254). Quito, Ecuador: Facultad Latinoamericana de Ciencias Sociales.

Mora, M. (2003). El riesgo laboral en tiempos de globalización. Estudios Sociológicos, 21(3), 643-666. Recuperado de https:// www.redalyc.org/articulo.oa?id=59806306

Núñez, L., Féliz, A., Paschoalino, I., Silva, J., Masson, R., \& Nathan, B. (2017). Subsistemas fronteriços do Brasil: mercados ilegais e violência. Santana do Livramento, Brasil: Laboratório de Estudios e Pesqusas Internacionais e de Fronteira, LEPIF.

Osuna, M. (2013). Estigma social en madres puertorriqueñas usuarias de heroína: una exploración de las voces femeninas y su entorno social. Revista Puertorriqueña de Psicología, (24), 1-17.
Parra, J. (2013). Complicaciones de lo ilegal y de lo informal: el Business, una propuesta conceptual. Antípoda. Revista de Antropología y Arqueología, (17), 205-228

Pérez, J. (2003). Globalization, upgrading, and small enterprises: A view from Central America. Competition and Change, 7(4), 205-221. doi: 10.1080/1024529042000197686

Pérez, J. \& Andrade-Eekhoff, K. (2003). Local Development: in the Global Economy. NACLA Report on the Americas, 37(3), 40-45. doi: 10.1080/10714839.2003.11724531

Pérez, J. \& Mora, M. (2004). De la oportunidad del empleo formal al riesgo de exclusión laboral. Desigualdades estructurales y dinámicas en los mercados latinoamericanos de trabajo. Alteridades, 14(28), 37-49. Recuperado de http://www.redalyc. org/articulo.oa?id=74702804

Portes, A. \& Haller, W. (2004). La Economía Informal. Santiago de Chile: CEPAL.

PRESIDENTE DE LA REPÚBLICA VS GOBIERNO REGIONAL DE TACNA, Exp. No 0031-2005-PI/TC (20 de marzo de 2007)

Quijano, O. (2016). (Neo)Liberalismo, Producción y Criminalización de la Pobreza. En F. Codoceo \& F. Ampuero (Eds.), Criminalización de la Pobreza. La construcción política del sujeto peligroso (pp. 43-58). Osorno: Editorial Universidad de Los Lagos.

Rabossi, F. (2004). Nas ruas de Ciudad del Este: Vidas e vendas num mercado de fronteira. (Tesis de Doctorado). PPGAS, Museu Nacional. UFRJ, Rio de Janeiro.

Radcliffe, S. \& Webb, A. (2016). Mapuche youth between exclusion and the future: protest, civic society and participation in Chile. Children's Geographies, 14(1), 2-19. doi:10.1080/1 4733285.2014.964667

Real Academia Española. (2005). Diccionario de la Lengua Española. Madrid, España: Real Academia Española.

Ríos, V. (2006). The hyper-criminalization of black and latino male youth in the era of mass incarceration. Souls: a critical journal of black politics, culture and society, 8, 40-54.

Rosenbluth, G. (1994). Informalidad y pobreza en América Latina. Revista de la CEPAL, (52), 157-178. Recuperado de https://www.cepal.org/es/ publicaciones/11941-informalidad-pobreza-america-latina

Svampa, M. \& Pandolfi, C. (2004). Las vías de la criminalización de la protesta en Argentina. Observatorio Social de América Latina, (14), 285-296.

Tacna: contrabandistas fueron sentenciados a 4 años de prisión y al pago de 13 mil soles. (26 de febrero de 2017). Diario Correo Tacna. Recuperado de www.diariocorreo.pe

Tapia, M., Liberona, N., \& Contreras, Y. (2017). El surgimiento de un territorio circulatorio en la frontera chileno-peruana: estudio de las prácticas socio-espaciales fronterizas. Revista de Geografía Norte Grande, (66), 117-141. Recuperado de http://scielo.conicyt.cl

Valdebenito, F. (2018). Capitalismo, espacio y geografía en la frontera peruano-chilena contemporánea (segunda década del siglo XXI): hacia una escala de la urbanización fronteriza tacno-ariqueña. Revista chilena de antropología, (37), 287-309. doi:10.5354/0719-1472.2018.49517

Valdebenito, F. \& Guizardi, M. (2014). Espacialidades migrantes. Una etnografía de la experiencia de mujeres peruanas en Arica (Chile). Gazeta de Antropología, 31(1). Recuperado de http:// dialnet.unirioja.es 
Vega, L. (21 de octubre de 2012). Aduanas no cumple trabajo em controles. (21 de octubre de 2012). Diario Correo Tacna. p.4

Wacquant, L. (2004). Las cárceles de la miseria. Buenos Aires, Argentina: Ediciones Manantial.

Wacquant, L. (2010). Castigar a los Pobres. Barcelona, España: Ediciones Gedisa.
Women in Informal Employment: Globalizing and Organizing (WIEGO). (2015). Mitos y realidades sobre la economía informal y las trabajadoras que laboran en ella. Recuperado de http://www.wiego.org 


\section{Notas al final}

1 Tacneño, de la ciudad fronteriza de Tacna (Perú). Esteño, de Ciudad del Este (Paraguay). Si bien ha habido estudios sobre Tacna y Ciudad del Este (Rabossi, 2004; Masi, 2017) estos presentan mayor evidencia desde Chile y Brasil. Así, el estudio de Ciudad del Este se concentra en el Micro Centro de Ciudad del Este (Rabossi, 2004; Masi, 2017), mientras que el estudio de Tacna en el centro de la ciudad, recibiendo mayor atención que otras dinámicas socio territoriales fronterizas y periféricas.

2 La ubicación de las Ferias de Ropa y Calzado de Segundo Uso se da en los distritos de Ciudad Nueva, Alto de la Alianza y Gregorio Albarracín, mientras que el Mercado de Abastos de Ciudad del Este se encuentra ubicado fuera del Micro Centro, en el Barrio Obrero de la ciudad.

3 Es importante anotar que, como estudio comparado de fronteras, el proceso de observación participante resultó más profundo en la ciudad de Tacna que en Ciudad del Este. Si bien se desarrolló el trabajo de campo en ambas ciudades, debido a motivos de residencia permanente del investigador se tuvo mayor éxito en la ciudad andina.

$4 \quad$ Cfr. Rabossi (2004) para el escenario paranaense.

$5 \quad$ Cfr. Rabossi (2004), Cardin (2006), "Tacna: contrabandistas fueron” (2017).

$6 \quad$ Cfr. "Hallan carro con ropa", 20117; Cardin, 2006.

$7 \quad$ Cfr. Vega (2012), Rabossi (2004).

8 Proveniente de sacola (bolsa), en referencia a quienes pasan mercaderías de un lado a otro en la Triple Frontera del

Paraná.

9 "Persona que vende, con tienda o sin ella, ropas, vestidos viejos, y baratijas usadas" (Real Academia Española, 2005:1350). La información de la actividad de los ropavejeros en la frontera Tacno Ariqueña, además de ser corroborada en las entrevistas, se encuentra referida bajo el término cambio casera por Fernando Graña (2011).

10 El Tratado de Lima de 1929 pondrá fin a la disputa de Perú y Chile por las provincias de Tacna y Arica, retornando la primera al Perú y permaneciendo la segunda en Chile.

11 "Las zonas de frontera pasaron de tener un tipo de valor instrumental a otro, en el sentido de que la hegemonía militar y territorial es desplazada con el neoliberalismo por hegemonía del container y los flujos entre las transnacionales" (Grimson, 2004, p.18).

12 Centros de Exportación, Transformación, Industria, Comercialización y Servicios, en las ciudades de Ilo (Moquegua), Matarani (Arequipa) y Tacna (Tacna).

13 "En el marco de una política económica y social de carácter nacional, el ejercicio de la libertad de comercio, de empresa y de industria debe guardar armonía con el principio de libre competencia; en ese contexto, compete al Estado cautelar las reglas para su normal funcionamiento. Esta consideración resulta importante puesto que al permitirse la importación de ropa y calzado usados, se aumenta la oferta interna de estos bienes, con la consiguiente disminución de sus precios a un valor irreal, consecuencia de la competencia prohibida.

La Ordenanza Regional Nº09-2005-CR/GOB.REF.TACNA vulnera directamente el artículo $7^{\circ}$ de la Constitución en cuanto la ropa y calzado usados contienen agentes químicos y biológicos que afectan a la salud pública. En esta línea de pensamiento, con la incorporación de Perú al Convenio de Basilea sobre el control de los movimientos transfronterizos de los desechos peligrosos y su eliminación, se implementó una política internacional para el tratamiento de los desechos en función de su peligrosidad, teniendo la ropa usada condición de desecho, conforme al Anexo B del referido Convenio." (Presidente de la República vs Gobierno Regional de Tacna, Exp. N 0031-2005-PI/TC, 20 de marzo de 2007).

14 Para obtener una visión más puntual del intercambio fronterizo debe tomarse en cuenta la legislación brasileña, particularmente la Lei 2.105/07 proyecto que, en el año 2007, instituía un Régimen de Tributación Unificada (RTU - Regime de Tributação Unificada) en la importación de mercaderías provenientes de Paraguay (Cfr. Jiménez, 2018; Cardin, 2006).

15 Resolución $\mathrm{N}^{\mathrm{o}} 671$ (17 de diciembre del 2014) por la que se establece normas complementarias para la vigencia y aplicación de los procedimientos y mecanismos de control del ingreso de mercaderías bajo el régimen del despacho simplificado de tráfico vecinal fronterizo.

16 Federación de Taxistas de Ciudad del Este. 